\title{
Capacity for Carbon Sequestration and Climate Change Mitigation in Different Ecologically-Distinct Zones of Sri Lanka
}

\author{
W.A.J.M. De Costa ${ }^{*}$, G. Murray-Tortarolo ${ }^{2}$, A. Harper ${ }^{2}$, S. Sitch ${ }^{2}$ \\ ${ }^{1}$ Department of Crop Science, University of Peradeniya, Sri Lanka \\ ${ }^{2}$ University of Exeter, Exeter EX4 4QF, United Kingdom \\ *janendrad@gmail.com
}

\begin{abstract}
Vegetation has the capacity to mitigate greenhouse gas (GHG) induced climate change by absorbing and sequestering carbon dioxide, the principal GHG, in plant biomass. Sri Lanka, an island located in the humid tropical South Asia, has a considerable range of ecologicallydistinct zones (EDZs) as a result of the spatial and temporal variation of its climate. These EDZs are characterised by different dominant vegetation types and ecosystems with varying ground cover. Hence, the carbon sequestration capacity which determines the strength of the 'land carbon sink' is likely to vary in the different EDZs. Analysis of long-term climatic data has shown that trends of climate change (i.e., increasing atmospheric temperature and potential evapotranspiration and decreasing precipitation and soil water availability) of the different climatic zones of Sri Lanka reflect the established global trends. These trends in climate change are likely to modify the carbon sequestration capacity of different EDZs over time. Therefore, the objective of this work is to estimate the carbon sequestration and climate change mitigation capacity of different EDZs of Sri Lanka and its historical variation to determine the possible impacts of climate change.
\end{abstract}

Simulations from nine dynamic global vegetation models (DGVMs) were used to estimate carbon balance parameters such as net primary productivity (NPP), heterotrophic respiration $(\mathrm{Rh})$ and net biome productivity (NBP) for eight $1^{\circ}$ (latitude) $\times 1^{\circ}$ (longitude) grid cells covering Sri Lanka. Models were run over the period from 1900 to 2009 using the climate forcing data from CRU-NCEP, which were validated using data from the Meteorology Department of Sri Lanka. Carbon balance parameters were calculated for six ecologicallydistinct zones of Sri Lanka (i.e., south-west, central highlands, eastern coastal plain, northwest, north-east and north) that were defined based on $1^{\circ} \times 1^{\circ}$ grid cells. A validation check of the model outputs was done by comparing simulated NPP with actual NPP for selected vegetation types. An initial analysis of all nine DGVMs, which included models running at different resolutions $\left(3.75^{\circ} \times 2.5^{\circ}, 2.5^{\circ} \times 2.5^{\circ}\right.$ and $\left.0.5^{\circ} \times 0.5^{\circ}\right)$ showed substantial within-zone variation and did not clearly distinguish carbon sequestration capacities of different EDZs. This was probably because of spatial averaging of outputs from coarse resolution models across different EDZs. A second analysis with the four finer resolution DGVMs showed substantially improved results. Subsequent simulations running the fine resolution model JULES on a finer grid of $0.5^{\circ} \times 0.5^{\circ}$ allowed estimation of carbon balance parameters in thirtyfive $0.5^{\circ} \times 0.5^{\circ}$ cells, which substantially-improved the spatial resolution of estimated carbon sequestration capacities of different EDZs of Sri Lanka. Temporal and spatial trends of the estimated carbon balance parameters will be presented along with analyses of their underlying causes and climatic drivers.

Keywords: Terrestrial carbon balance, Net primary productivity, Climate change, Sri Lanka

Proceedings of the International Forestry and Environment Symposium 2015 of the Department of Forestry and Environmental Science, University of Sri Jayewardenepura, Sri Lanka 